\title{
Urban frontiers in the global struggle for capital gains
}

\section{Peter Mörtenböck}

Goldsmiths, University of London, UK

\section{Helge Mooshammer}

Goldsmiths, University of London, UK

\begin{abstract}
This article examines different ways in which finance models have become the ruling mode of spatializing relationships, arguing that the ongoing convergence of economic and spatial investment has transformed our environments into heavily contested 'financescapes'. First, it reflects upon architecture's capacity to give both material and symbolic form to these processes and considers the impacts this has on the emergence of novel kinds of urban investment frontiers, including luxury brand real estate, free zones, private cities, and urban innovation hubs. Focusing on speculative urban developments in Morocco and the United Arab Emirates, the article then highlights the performative dimension of such building programs: how architectural capital is put to work by actively performing the frontiers of future development. Physically staking out future financial gains, this mode of operation is today becoming increasingly manifested in urban crowdfunding schemes. We argue that, far from promoting new models of civic participation, such schemes are functioning as a testbed for speculation around new patterns of spatial production in which architecture acts less as the flagstaff of capital than as a capital system in itself.
\end{abstract}

\section{Keywords}

Urban speculation, architectural capital, frontier processes, luxury real estate, crowdfunding

\section{Introduction}

For the modern capitalist economy of the past 200 years, progress, as measured by the establishment of new markets, has been intrinsically linked to the speculative opening up of new spaces. Strategies involved in these operations range from expanding the market 
economy's reach into new territories (e.g., global trade, microfinance) and securing new resource supplies (e.g., colonialism, modern-day forms of land grabbing) to restructuring modes of socio-economic organization (e.g., suburbanization, outsourcing). ${ }^{1}$ The successful promotion of suburbia in the mid-twentieth century, for instance, was paralleled by a boom in the production of mass commodities that supported this way of life, from cars to fridges and TVs. What distinguishes the current situation is a growing financialization of non-financial domains - housing, recreation, education, health, and so on - brought about by the rise of finance capitalism since the mid-1980s (Sassen, 2012). The subsequent surge in demand for investment opportunities by rapidly swelling pools of international capital has led to a focus on architectural spaces as investment securities, with an emphasis on the promise of future market potential rather than conventional collateral backed by an underlying use value. Eclipsing issues of social responsibility, environmental sustainability, and economic justice, the primary purpose of building becomes the lubrication of financial trade. With this shift of interest, in which the rationale of financial investments is increasingly directed toward their own logics, cities become the by-product of investment maneuvers and surrogates of equity speculation (Dunham-Jones, 2009).

A crucial consequence of the ongoing naturalization of 'financialized valuation' (Chiapello, 2015: 13-35) is that urban life in the present becomes subordinate to an economy of future options (Esposito, 2011). In light of the far-reaching social implications that accompany the remodeling of our cities as a volatile asset class, there is mounting pressure to grasp how architectural spaces are instrumentalized as a theater of speculative investment. While spectacular architecture and towering skylines, as in the case of the Persian Gulf city of Dubai, may serve to underscore the economic force of urban development, it is the phenomenon of 'Dubaization' (Elsheshtawy, 2010: 249-255) and its different variants - ever-evolving processes of abstraction and imitation, amplification and multiplication, manifesting themselves in market-friendly, globally compatible "spatial products" (Easterling, 2005: 1) that we need to engage with in order to address the global spread of supply-led speculative urbanism following the turn of the millennium. Even though these 'splintered' styles of urban development have been implicated in the rise of the real estate bubbles that led to the global financial crisis in 2007/8, this experience has not brought an end to this investment model (Graham and Marvin, 2010: 33-36). Rather, we are seeing a higher concentration of investment in specific locations and types of development that are increasing social division by generating customized enclaves for global capital in urban cores that contrast starkly with overpopulated and impoverished urban peripheries (Merrifield, 2014).

The rapidly growing number of such strategically placed and globally marketed urban developments in cities around the world, from London and New York to Mumbai and Jakarta, highlights how architecture's engagement in capitalist economies has changed from speculation with spatial production to spatial production for speculation. The 'performance targets' of architectural spaces designed to fuel the flow of speculative capital are very different from those of architecture designed to serve the needs of capitalist production, and it is these changes in the 'performance' of architecture - the financialization of architecture and its orientation toward dynamic frontier processes - that this article will focus on.

\section{Architecture as capital}

In economic terms, capital typically refers to wealth used in profit-making. Pierre Bourdieu's (2005) extension of the term from the economic arena to a broader set of assets, including 
the symbolic, cultural, and social spheres, has proved to be a turning point in the way we think about the creation, accumulation, and circulation of wealth. The notion of symbolic capital in particular has helped to articulate the affective dimension of capital, which is connected to the ways in which human and non-human actors, including the built environment, can accrue value through contextual prestige, distinctiveness, and recognizability. Recent studies on the changing character of capitalist economies have emphasized the increasing role of communicative and relational assets, whose ability to attract investments relies on the skilful introduction of affective factors into the circuits of capital accumulation (e.g., Marazzi, 2011).

The term 'capital' is employed in our analysis of speculative spatial production in this extended sense, one that is already implied in its original dual meaning. Derived from its Latin root caput (head), capital points to both a particular form of management and a specific order of power and vitality. It is both productive means and signification. This dual character of capital manifests a crucial link between the operative and communicative dimensions of spatial production, between material occurrences and ideational gestures. In classical architecture, the capital mediated between the column and the load it supported. A highly ornamental joint, the capital played a vital role in monumental buildings by channelling forces and concentrating power. As such, it was one of the clearest indicators of the classical architectural order. While this particular articulation of capital has taken on a different form in contemporary architectural language, the nexus of operative and communicative domains in designing the built environment still prevails.

In today's context of global financial markets, the linkages between material and symbolic values can provide a decisive anchor point for studying contemporary investment strategies centered on fusing economic and spatial development in processes of 'building capital'. To address these dynamics, we want to shed some light on how newly conceived asset configurations that revolve around the building of urban investment opportunities have begun to enact spatio-economic frontiers, i.e., environments characterized not only by investment and speculation per se, but by an entire system of extensive and intensive expansion through strategic spatial experimentation and risk-taking (Mezzadra and Neilson, 2013: 67-68). In this context, it is important to note that the frontier is not a given space, but rather created through a series of advances aiming to structure a field of options. These processes entail systematic and well-placed operations, techniques of interruption and evasion, accumulated protocols and rituals, radical gestures and expressions, coded values and aesthetics. Urban frontiers, in particular, are currently manifested at the contact points between new areas of economic endeavor and the established realities of a society. Such frontiers are increasingly marked by a wide range of 'spatial products': patterns of architectural form and spatial organization that are bundled together with financial incentives, statutory privileges, and cultural aspirations tradable packages to place bets on the future (Mörtenböck and Mooshammer, 2016).

There is an evolving plurality of such spatial products, ranging from the excessive cultivation of metropolitan landscapes as 'global lifestyle destinations' and the rise of free zones, to the strategic bundling of knowledge-based start-up enterprises into a new model of city-making, and the proliferation of urban crowdfunding schemes, which are now attracting record levels of investment by 'ordinary' people. What connects the different areas of urban investment that are at stake here is the expansionist logic of capitalist markets and a continuous reliance on spatial restructuring to counter cycles of crisis - 'spatial fixes', in David Harvey's terminology (Harvey, 1981; 2001: 284-311). In this search for new markets and continuous investment opportunities, the wealth of whole regions has become epitomized by their spectacular building programs. The ensuing economic crises and political upheavals, however, have not brought about the fundamental change of urban development some might 
have hoped for. Rather, as we will see, attempts to capitalize on emergent forms of economic cooperation in the urban realm have proliferated, including those that were conceived as alternative responses to a crisis-prone market economy.

\section{Dreams of urban speculation}

The speculative investment in luxury real estate developments is arguably one of the most persistent examples of spatio-economic frontiers to have opened up in recent years. It has given rise to a worldwide boom in 'real estate portfolios' that build on an assemblage of luxury apartments, branded malls, and glamorous leisure destinations frequently anchored by images of spectacular city skylines and 'super-modern' urban infrastructures. In some European countries, the excesses of speculative real estate became most evident in the wake of the 2007/8 financial crisis, when swathes of construction sites were abandoned and millions of units remained unsold and uninhabited (Schönig and Schipper, 2016). Globally though, speculative investment in luxury real estate has picked up again, creating severe impacts on the livelihoods of millions of people (Datta and Shaben, 2016).

Capital may in essence be a social relation, but the recurrent increase of indebtedness, unstable housing, property-related unemployment, and other dimensions of urban poverty demonstrate how human relationships are more and more interwoven with a complex range of infrastructures - dynamic arrangements of profit-making assets, buildings, goods, and images. Just as urban frontiers themselves are more an infrastructural arrangement - a movement of capital - than an object, the asset values linked with them represent a scenario of constant movement, rather than a fixed, immobile object. Urban investment opportunities are always threatened by the collapse of their investor appeal; they struggle to uphold the power of their appearance by creating an affective tapestry of celebrations, anticipated profits, and rumored glory.

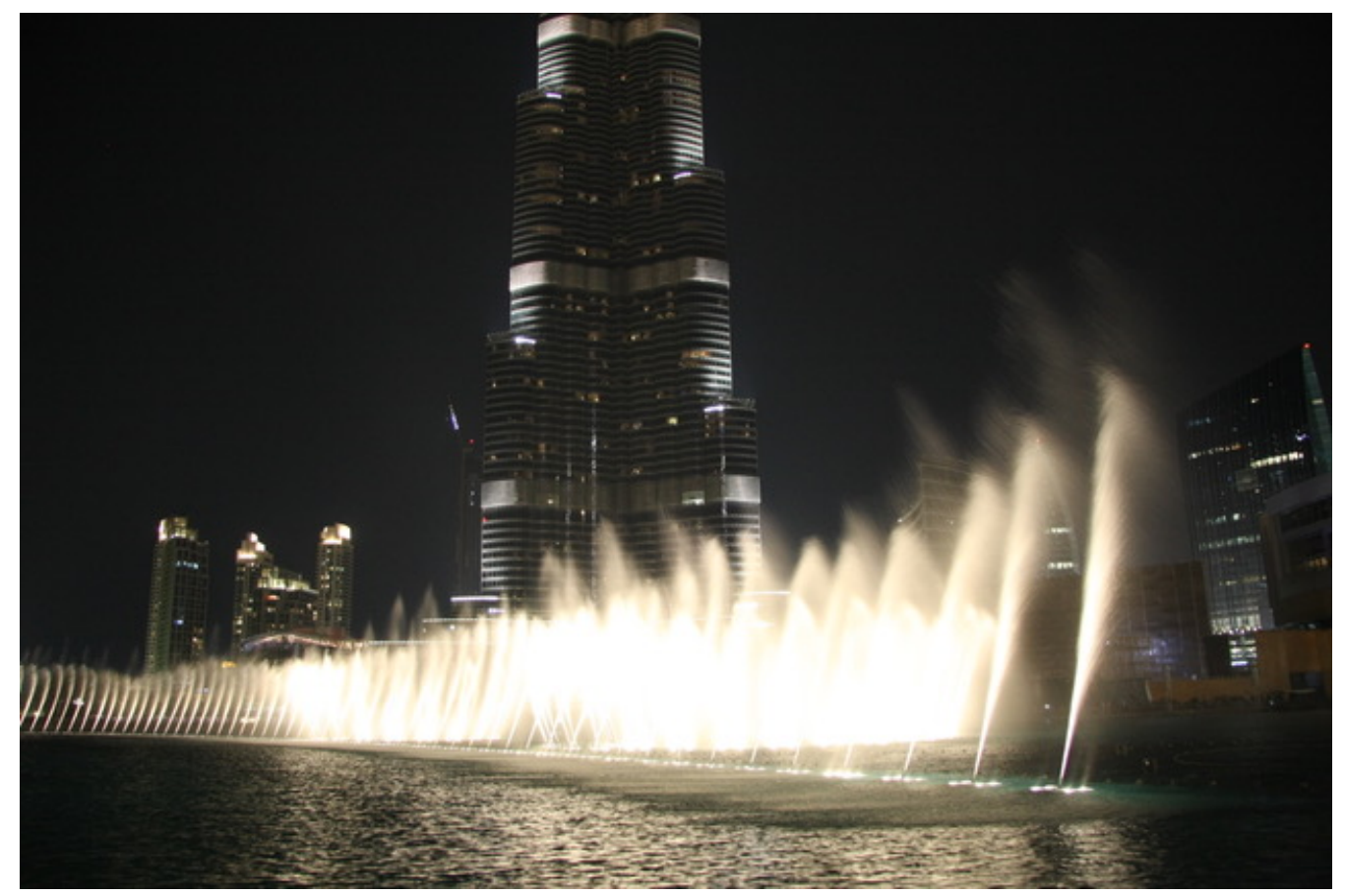

Figure 1. Dubai Downtown, United Arab Emirates, 2014. Photo by Mörtenböck and Mooshammer. 
A critical case in point for these entanglements is Dubai, whose speculative urbanism has mushroomed along the shoreline of the entire United Arab Emirates and beyond, scripting a repertoire that other competitors attempt to mimic or exceed. The prestigious Burj Khalifa, presently the world's tallest building, provides luxury housing and office spaces, along with shopping, entertainment, and dining, in the prime Downtown Dubai development. Affluent investors from India, who own almost $20 \%$ of the 900 apartments in the tower, have recently been joined by a buyer elite from countries affected by the Arab Spring and other antigovernment protests, such as Egypt, Iran, or Lebanon, in search of safe havens for their funds (Dubai Land Department, 2016). Every night, Burj Khalifa is bathed in the glittering lights of the famed dancing fountains that erupt at its feet to the sounds of Andrea Bocelli and Sarah Brightman's 'Con te partirò', the Arab dance hit 'Shik Shak Shok', and Lou Reed's 'Walk on the Wild Side'. But a little more than a half hour's drive away, the construction site of Emirates City - another development envisaged to include picturesque lakes and parks, lavish shopping facilities, mosques, five-star hotels, and educational and medical facilities - stands deserted. Sand-shrouded, the only living creatures in the vicinity are a few camels grazing along its perimeter. Both sites were born out of the same investment boom after the turn of the millennium that attracted expatriates of various nationalities, especially Indian, British, and Pakistani, to buy properties in the United Arab Emirates (UAE), yet they seem worlds apart. ${ }^{2}$ While the Burj Khalifa stands as a shining testimony to the global power of real estate speculation, Emirates City - employing similar sales tactics but operating on lower levels of investment - fell victim to the financial collapse of 2008, when mortgage flows needed for its completion dried up. Located ten miles inland, in Ajman, the smallest emirate in the UAE, this monstrous gathering of concrete has become a monument to the shattered dreams of smallscale investors from Iran, Pakistan, India, and Middle Eastern diasporas across Europe and North America.

Strategically positioned directly along Emirates Road, a key traffic corridor in the UAE, Emirates City was one of the last schemes to jump on the Dubai bandwagon of glamorous supply-led development. Racing to outdo each other in demonstrating economic vitality through breathtaking architectural gestures, real estate development companies competing for Arab and non-Arab investors produced such grand visions as the gigantic Palm Jumeirah land reclamation project, which was followed by the even grander Palm Jebel Ali and Palm Deira proposals, and the now-stranded islands of The World. These interrelated large-scale developments tried to emulate the earlier success of developments such as Downtown Dubai or Dubai Marina by way of borrowing, replicating, and amplifying such infrastructural typologies as gated communities, business districts, or waterfront developments (Ramos, 2010: 140-63). In keeping with this spirit, the master plan of Emirates City envisaged the construction of around 72 mostly residential towers bearing evocative names such as Paradise Lake Towers, Goldcrest Dreams, and Fortune Residency Tower. But work on the site commenced only a few months before the onset of the global financial crisis and was soon halted thereafter. A handful of towers were topped out but most were abandoned at half height, while others barely rose above their foundations. In spring of 2014, a few workers were hired to infrequently attend to the site and give the impression of progress in order to fend off legal or government interventions, and to convince investors to resume their payments. In many places, the concrete skeletons had already fallen into severe disrepair, with reinforcement girders laid bare by erosion. Although several towers have now been completed and work on other towers has slowly picked up, a pattern emerges that echoes the dynamics of other international investment hubs: while successfully branded urban centers such as Downtown Dubai are 
attracting global interest and prices are spiraling upward once again, peripheral sites such as Emirates City are being left behind.
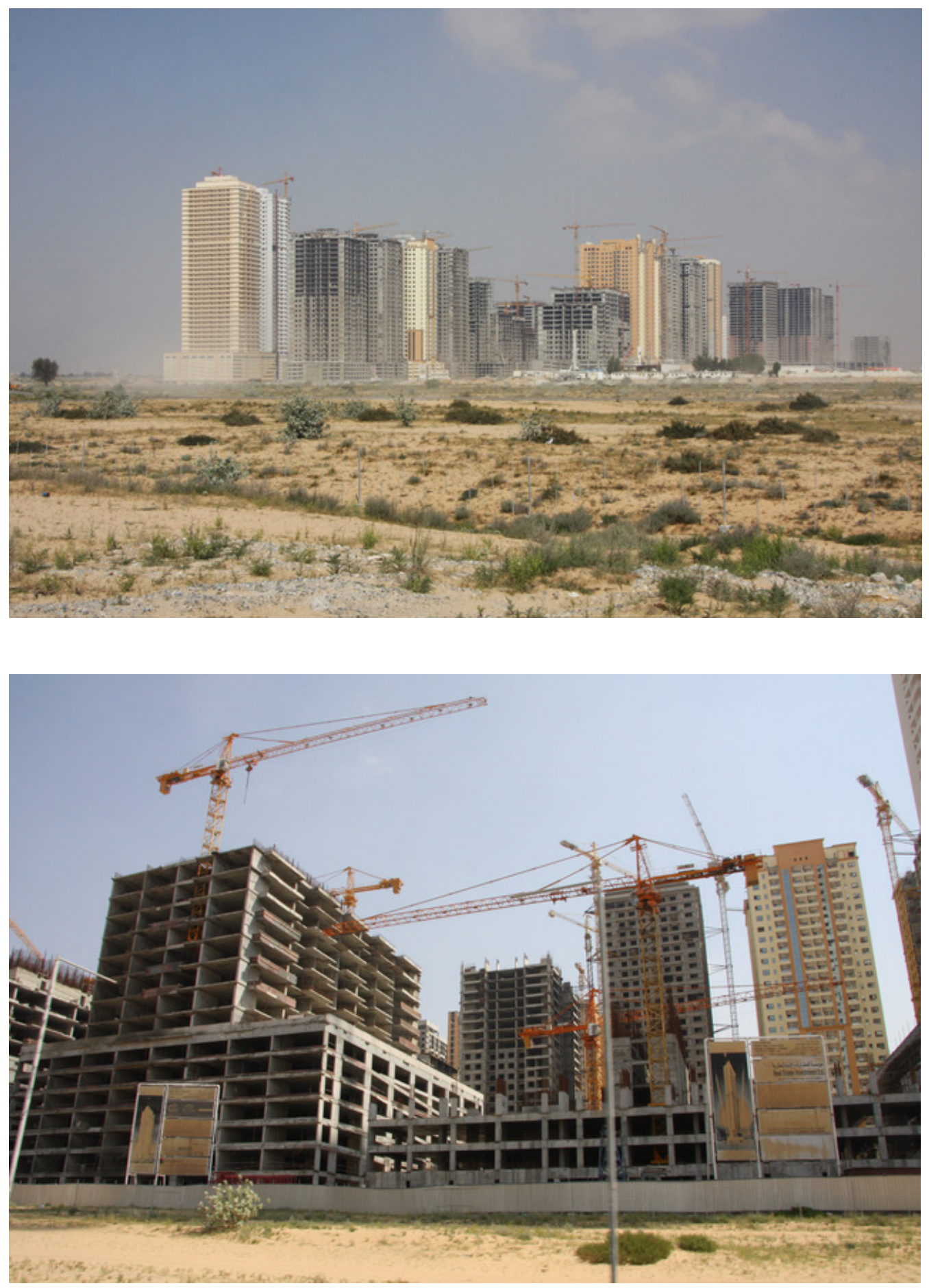

Figures 2 and 3. Emirates City, United Arab Emirates, 2014. Photos by Mörtenböck and Mooshammer.

Even those towers that appear finished on the outside remain uninhabitable, and investors cannot take possession of their property because Emirates City lacks the most rudimentary infrastructure, such as road access. In stark contrast to the glossy advertisements depicting solitary skyscrapers amid greenery on the shores of an artificial lake, the ghostly structures are packed close together like a nightmarish vision of Blade Runner in the desert. None of the 
towers sport the advertised glamorous crowns of penthouses or iconic architectural features. The monotonous replication of the same template of podium-towers - bland apartment floors sitting on top of a multilevel parking structure - adds to their alien appearance and disconnection from the desert surroundings. Looking at the plans, it becomes clear that the vision of an 'avant-garde lifestyle' would never have materialized even if building had been completed. ${ }^{3}$ Ignoring the fact that the towers are located in the middle of nowhere at a density that rivals Asian cities such as Hong Kong or Singapore, tight one-bedroom apartments were sold as free-floating commodities valued in terms of unit numbers and promised amenities.

Iranians and members of the Indian diaspora from southeast Africa, along with the odd European investor, were lured to this fictitious environment, risking their life savings by the combination of 'true 100\% freehold ownership' (a popular advertising slogan on numerous property websites at the time of writing) and the promise of resident visas for the immediate family. But hopes for residency were dashed when, in 2008, the government of Ajman renounced the prospect of residency visas for property investors, causing a further drop in market values (Al Jandaly, 2008). Since then, blogs have been awash with the concerns of remote investors still clinging on to promises of resumed building work and desperately trying to get hold of some real value, fighting their way through the online jungle of property resale and swap deals. ${ }^{4}$ On the ground, the stagnating building site is screened off from passersby on Emirates Road by a giant billboard emblazoned with, in large golden letters, the rather ambivalent slogan, 'It can only grow BIGGER the next time you pass by'.

The sites of Downtown Dubai and Emirates City indicate, on the one hand, the triumphant excess of the politically administered 'liberalization' of global capital flows and, on the other, the many casualties left in the wake of its cycles of boom and bust. What binds their fortunes together is how an architectural aesthetics that signals luxurious quality and style is being deployed to connect actors from around the world and to tie their wealth to property options based solely on financial speculation. In our current era of what may best be described as 'affective capitalism' - tapping, channeling, and directing capital flows by utilizing emotional ties - contemporary architecture is increasingly implicated in the maneuvers and manipulations of speculative economies, and in the process is being transformed from a physical environment in which human lives are lived into a mode of operation.

\section{Performing spatial investment}

Although architecture is widely recognized as a major player in the operations of global capital, it is too often treated merely as an object of speculative capital investment or a reflection of uneven wealth distribution. Particularly since the recent collapse of the financial bubble to which architecture had given shape and space, the built environment has increasingly been presented as an illustration of crisis, with images of ghost towns built during the boom years, such as Emirates City, encapsulating the catastrophic impacts of financial speculation, environmental degradation, and social injustice. Foreclosure imagery evokes a sense of uncanniness, one that exposes the alienating logic of real estate speculation. The form of temporality captured in such photographs is marked by credit relations fraught with poorly considered expectations of profitability. Owners are left estranged from the anticipated values embodied by their property, since these buildings have never become 'real' in the sense of being appropriated as inhabitable structures (McClanahan, 2016: 135-40). It is for this reason that ghost towns are often said to represent the failed attempt of speculative urban developments to surmount the crisis of changing economic environments by offering a 
supposedly secure and solid piece of the future. However, engaging with architectural production according to this illustrative logic not only narrows the scope of our understanding of global economic processes and spatial developments but also obscures the ways in which architecture performs.

In its contemporary configuration, capital needs to be put to work in order to cultivate opportunities and to earn a return on an investment. On one level, this implies that capital produces a repertoire of efforts to bring together human and non-human actors to generate the knowledge and capacity that are purportedly required to effect change. On another level, 'put to work' refers to the ways in which the production of space actively performs the frontiers of future development by moving and displacing concepts and signs from one field to another, connecting the world's most prosperous regions with far-off emerging economies and the pioneer spirit of the past with early twenty-first-century representations of an imagined future. As a powerful force within a network of interrelated practices, architecture is always doing something and thus producing observable traces, from staking out territorial claims and consuming premium locations to unbundling existing infrastructures so as to develop and control high-capacity domains. Within this matrix of operations, architectural capital is not confined to a particular site; rather, it acts as a provisioning system that disaggregates and rechannels capital-generating forces, using its own set of protocols to transport materials, values, and agendas across fields ranging from the design of the built environment to the manipulation of resource flows, and from the physical manifestation of political ideologies to the territorial control of entire populations.

Architecture provides the technologies and cultural references to realize the combined economic-governmental vocation behind these developments. In the search for continuous investment opportunities, the employment of branded and replicated architectural aesthetics, commonly termed 'signature architecture', is underwriting the mobility of global funds. From the record-breaking pace of Dubai's changing skyline to Shanghai's booming special economic zone of Pudong and the stunning IT parks of many Indian cities, architectural vocabularies are helping script a narrative that champions the shift of investment from sites of production and habitation to asset portfolios.

The provisional and infrastructural quality of the architecture employed in these settings constitutes a mode of capital that not only enables the creation of new material habitats but also the emergence of 'financescapes' (Appadurai, 1996) - patterns of interaction crystallized into spatio-economic formulas that are replicated on a global scale. ${ }^{5}$ These sprawling landscapes, be it through the development of exclusive properties and record-breaking skyscrapers described above or the creation of alluring lifestyle features and values (island living, vibrant cityscapes, location independence), are manifested as a range of spatial patterns across territories that fuse multiple politico-economic interests with processes of subject formation. Lending both material and symbolic form to these processes, architecture impacts the emergence of new kinds of investment cultures. It provides the 'glue' for these globally occurring yet fractured developments. Today's urban investment frontiers radically combine communicative and operative efficacy. They fully embrace the capacity of what Michael Goldman (2011) calls 'speculative urbanism' to reconstruct the relationship between designers, investors, territories, and the public. A reconceptualized interplay of rules (government), cities (habitat), and economic development (investment structures) comes into force, yielding a growing range of experimental arrangements driven by the mobilization of design and material logistics.

At issue here is not a change in scale or form but a change from architecture understood as urban design to architecture understood as a medium of polity - a change in which 
architecture acts less as the flagpole of capital than as a capital system in itself. Tracing the current frontiers of investment structures therefore needs to take into account how capital organizes space according to a hierarchy of criteria. Contemporary philosophy has described the mechanics of these operations as an investment that enables structures to unfold based on an 'economic' sense of order; that is to say, an order that is guided not by substance but by relation. This kind of framework entails what Giorgio Agamben (2011: 141) calls the division between a 'general' and a 'particular' economy, the split between intellectual knowledge and praxis, remote authority and governmental action. ${ }^{6}$ This distinction can be applied to the rampant logic of the emerging frontier processes indicated above and the governmental efforts connected to them. These developments are giving rise to structures that depend largely on the production of trans-territorial symbolic and material arrangements that have more to do with each other than with the geographies in which they are located.

Interpreting architecture in this way - as an investment instrument with considerable volatility in the underlying asset value over time rather than a particular form of design raises questions about the logics and consequences of this globally active economy. One aspect that needs to be considered in this context is how the emergence of new spatioeconomic frontiers depends on interactions across varied distances, worldwide circuits of franchised commercial infrastructures, and the mobilization of global constituencies. Replicating the generic environments of luxury shopping malls, entering into strategic associations with global brands, hosting international sporting events - all these activities help to establish and maintain the frontier as an accommodating environment. Scrutinizing this performative dimension of architecture helps us understand how the intersections, anchor points, and nexuses of spatial development, finance, management, and communication are made manifest in an increasingly dynamic and elastic set of asset values pertaining to the spatial protocols and territorializing aspects of emerging global econometrics.

\section{Multiple times, multiple frameworks}

The narratives of spectacular skyscrapers, and the swathes of abandoned building sites that occupy their metaphorical, if not literal, shadows, are both potent reminders of the enormous influence of banking and finance over the urban environment. Finance economies have become a powerful motor not only of urbanization in gentrified or segregated areas of major cities, but of urban expansion in general. The worldwide replication of speculative developments has inscribed a global space of permanent crisis and emergency where the untamed realities of failed capital speculation keep breaking through. The subjective experience of such a condition is not only a spatial question but above all a question of duration, persistency, and abidance; a question of renewal, change, emergence, growth, and catalyzation. As Walter Benjamin (2010) argues in his theses on the concept of history, challenging the permanence of the state of emergency requires insight into the parallel existence of multiple times. Such a layered, non-homogeneous temporality, through which we enter into a range of affective attachments, confronts the collective situation of speculative urban development with temporal disjunctions, disjunctions that organize experiences differently. The endeavor to break into this structure, reorganize experiences and achieve a collective reorientation therefore constitutes the focus of progressively self-empowering urban movements (Adams, 2011, 2012). However, this progressive self-empowerment is more than merely a linear process. It is a type of collective action whose fleeting contours are orientated less to the actually perceptible than to a range of imperceptible qualities and potentials. It is precisely at this point of the empowerment of citizens as urban subjects, in the reality of its 
potential, that the decisive force of self-determined engagement with the city is expressed - in a relationally-activated preparedness for what may come about.

We can see this sense of urban reappropriation reflected 4,000 miles west of Dubai, on the Atlantic coast of northern Africa, where another ambitious development project has come to a standstill due to the crisis-prone irregularity of capital flows. Row after row of deserted roads, complete with street lamps, traffic signs, and a seemingly endless series of electricity boxes, protruding drainpipes, and curbs overgrown with weeds, produce a by-now-familiar trope of the residue of failed developments, replicated across much of the Mediterranean coast and other former investment hotspots that have gambled on property booms. While here, too, abandoned building sites are boarded up and almost-finished apartment complexes stand vacant, swathes of land fitted with infrastructure are slowly being filled informally with self-built dwellings on newly divided micro-plots sold to individual buyers by struggling developers. Tamansourt is one of fourteen villes nouvelles that were initially planned to be built throughout Morocco by 2020. In colonial times, the ville nouvelle was erected on the outskirts of the old medinas to house the foreign rulers in comfort and style. By contrast, this twenty-first-century ville nouvelle is intended to accommodate the expanding working class, and is typically planned as a satellite town situated out of sight of the urban center it is designed to serve.

Located seven miles west of Marrakesh and planned for 300,000 inhabitants, with a target population of 50,000 in 2013 , the purpose of Tamansourt was to relieve pressure on the tourist destination's bidonvilles - densely populated neighborhoods of informal dwellings and free up valuable space for areas dedicated to resorts around the old town, such as the offshoot of Ibiza superclub Pacha. The favored property-based model of large-scale development has borrowed not only strategies from the commercial US real estate industry, which have now spread from Dubai to China and from Moscow to Brazil, but also architectural typologies involving variations of gated communities with scaled-down private amenities, all built in an eclectic mix of (re)imported styles - aesthetic options range from Moorish to Spanish Revival and Contemporary Modern. The investment rationale shared across all these different sites produces a global architectural vernacular conveying a prestigious lifestyle irrespective of a property's actual status, or whether the style decorates a multimillion-dollar villa in California, a sea-view apartment in Dubai Marina, or an apartment in the deserts of Ajman or Marrakesh.

The employment of a commercial development model to provide mass housing is part of the ongoing assimilation of Morocco into global economic circuits. Markets targeted in this way range from municipal services and information technology to the tourism industry, which is being streamlined into the profitable brand of 'international style' five-star resorts - a fusion of Asian, Californian, and Mediterranean aesthetics implemented through design, amenities, and cuisine. In the case of Marrakesh, this model of speculative development successfully runs the market for holiday homes that is now widely accessible to foreign investors due to the proliferation of budget flight connections to Europe and beyond.

When the mortgage market for lower- and middle-income properties in Morocco dried up after 2008, developers in Tamansourt increasingly turned to selling plots rather than building apartments. In 2014, the cost of an empty lot of approximately 1,000 square feet, water and electricity services included, was equal to the price of an apartment of similar size $(180,000$ to 250,000 Moroccan dirhams, or circa US $\$ 18,300$ to 25,400 ) but afforded 'self-developers' the possibility of adding multiple stories according to their financial situation. The style of these new self-built structures differs markedly from that of the image-oriented commercial developments in Tamansourt. Aiming to optimize floor areas, they form solid three-to-four-story 
blocks of concrete brick walls occupying the entire plot with openings only to the streets and tiny inner courtyards. In fact, the building fabric of the 'urban village' arising on the layout of the initial plan closely resembles the densely built-up bidonvilles these villes nouvelles were meant to replace.
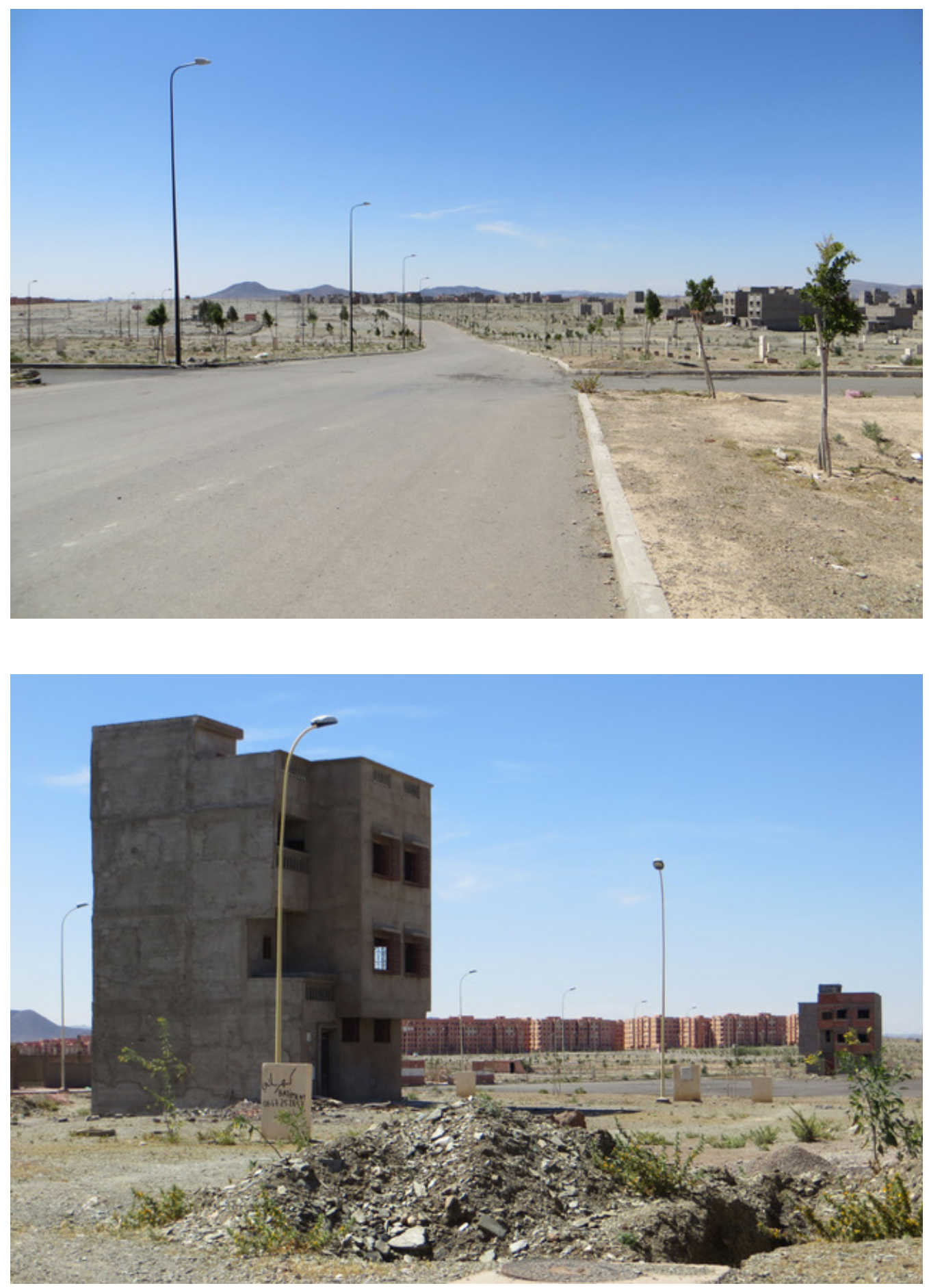

Figures 4 and 5. Tamansourt, Morocco, 2013. Photos by Mörtenböck and Mooshammer.

From (neo)colonial exploitation and experiments with new-town planning to the design of panAfrican infrastructures and modern-day landgrabbing, northern Africa has a history of providing a testing ground for all kinds of speculative urbanism. In the early 1930s, when Le Corbusier began his work on Plan Obus for Algiers, his anti-capitalist agenda of informed syndicalism led 
him to design an elevated highway with 14 residential levels beneath it, connecting a string of suburban areas. ${ }^{7}$ The residential levels were intended to be built as an infrastructural shell homes for 180,000 workers would then be constructed step-by-step, constituting a linear city. Fed by informal traditions of spatial expansion, the urban fabric emerging from Tamansourt's tabula rasa plan, though formally different to Corbusier's vision, embodies a strikingly related form of modular infrastructural appropriation over time, and could be taken as a reference point to deal with the thousands of housing units in 'ghost cities' all around the world that sit empty despite often being owned by investors.

\section{Frontier climates}

In the years since the 2007/8 financial crisis, there has been growing interest in the development of urban space through social media-based, bottom-up investment structures, such as real estate crowdfunding platforms (e.g., Massolution and Crowdsourcing.org, 2015). Experiments with these new spatio-economic arenas are redirecting investment by connecting novel financial instruments with innovations in communication (social media) and changing cultural understandings of urbanism ('right to the city'). Crowdfunded urban developments claim to offer 'ordinary' citizen investors an opportunity to participate in building the kind of urban habitats they desire. At the same time, by permitting individual investments that are often as low as $\$ 100$, crowdfunded real estate accesses a hitherto untapped pool of smallscale investment capital. ${ }^{8}$ While the volume of crowdfunded real estate is still comparatively small ( $\$ 2.5$ billion in the US in 2015), it has the potential to follow in the footsteps of other technology-driven processes of economic atomization such as online trading and micro-tasking (Howe, 2009).

These transformations are seamlessly integrated into a growing culture of crowdfunding and peer-to-peer industries ranging from social lending services (online borrowing and lending between individuals without a bank or building society involved) to human capital contracts (provisioning of private funds to an individual against a portion of the individual's future income). Exposing the limits of national jurisdiction and sovereignty in times of globalization, they have become possible as a result of a rapid spread of economy-driven terrae nullius, entrepreneurial circuits, and incentivized risk taking. Their framing as a kind of cultural liberation masks and renders taboo fundamental aspects of the circulation of capital: credit, debt, interest yield, speculation, the atomization and collectivization of risk. Direct financing of the 'desired city' by its 'citizens' is accompanied by tendencies toward a purchased imbalance in voting power and civic segregation based on cultural class preferences and the lifestyle choices of urban elites, since ostensibly bottom-up organized participation in the development of 'crowdfunded culture' is in most cases dependent on individual access to financial means.

What is emerging in this frontier climate are new connections between real estate, engineering, creative industries, commerce, media, governance, and politics. Aligned to shifting trajectories and forms of investment, this culture consists of new kinds of cooperation between actors who have little experience collaborating with one another but hope their joint operations will open up unforeseen opportunities for everyone involved. Their 'hit and run' strategies, as AbdouMaliq Simone (2010: 161-62) has described the interventions implied by this process, provoke an organizational logic that is being embraced as a new model of urbanism and stabilized as a new political paradigm. As a bottom-up model, "crowdfunded urbanism' combines two dynamics of urban development that have hitherto been understood as antithetical: self-organized initiatives regarding the design of the urban environment, and speculative investment. Capitalizing on the widespread success of social fundraising platforms 
such as Kickstarter and Indiegogo, a plethora of crowdfunded urban projects ties funding processes closer to the production of new urban environments and immerses creative practices directly within social networks, thus securing attention and reception. In the eyes of many, this new model of financing urban projects is therefore seen to be a significant step towards a more 'unmediated' (but consequently also less safeguarded) approach to citymaking.

The Washington-based crowdfunding platform Fundrise and the New York-based Prodigy Network were among the first crowdfunding platforms specializing in such campaigns ('the idea', says the latter, 'is to create a compelling story about the opportunities now available for regular people to fund huge real estate projects'). Claiming to generate entirely new social contracts based on a culture of venture capital and civic risk taking, the diverse range of conspicuous projects currently under development are raising new questions about economic power, social control, and cultural elitism. ${ }^{9}$ Rather than securing independence from established institutions and economic powers, to what extent is this model simply a continuation of the ongoing privatization and financialization of the public sphere? Hinging participation on monetary investment, are these frontier processes of contemporary citymaking not only contributing to an un-democratizing of access to urban participation, but also constituting an evolving mode of capital, one that turns the definition of civic values into a playground for social elites?

Notably, the aesthetics of crowdfunded urbanism ties into the relational language of social media, rewarding an investment not only with financial returns based on the amount invested, but also with the promise of becoming part of a community. Key for all campaigns is a direct personal address to 'you', delivered and adorned by a vis-à-vis that literally has a face and a voice: 'Decide for yourself!' or: 'It's up to you what happens in your neighborhood'. Even if the product is building the country's tallest skyscraper, the emphasis is on a 'villagey' feeling that conjures belonging and civic engagement, in contrast to the cold anonymity of glossy urban investment. Key phrases in the public relations campaign for the BD Bacatá tower in Bogotá, billed as 'the biggest product in the world', include:

The Eiffel Tower was financed by Gustave Eiffel, the Empire State by John Jakob Raskob and Pierre Dupont, the Burj Khalifa was financed by the Sheik Mohammed Bin Rashid Al Maktoum, and the people who are funding the tallest building in Colombia are - they are thousands of Colombians who believed in a way to make history in their city without depending on major corporations.

Funded not by 3 tycoons but by over 3,000 ordinary Colombians.

Revolutionize the consumer's power. Giving the opportunity to the $99 \%$ of playing a leading role in the future of their city. ${ }^{10}$

This orientation resonates with the increasing attachment of finance capital flows to affective capital. The generation of emotions has become the decisive factor in how new growth markets are steered. In order to attain their financing goals, crowdfunding projects therefore emphasize the creation of specific cultural values, such as the pleasure of social solidarity, the pride in one's own neighborhood, the possibility of creative expression, and the power of self-determination. Given the unabated popular desire to invest in the supposedly 'safe' domain of real estate and upcoming changes in many countries' legislations (following the crowdfunding exemption under the 2012 JOBS Act, access for ordinary people, including foreigners, to direct online investment schemes is expected to be further liberalized in the US), this market is set to experience significant growth over the coming years. While such 
innovations in entrepreneurial finance will never be responsible for the majority of the built environment, they have a disproportionate effect on the social and economic fabric of the city because the innovation sector has the largest multiplier effects of all sectors (Moretti, 2012), especially since 'asset urbanism' - the idea that buildings are now primarily used as investments to expand individual and community economic wealth - is itself sometimes seen as an innovative form of city-making (Soules, 2016: 199-210).

\section{Time to rebuild the foundations of urban investment}

Their contrasting appearances notwithstanding, urban crowdfunding initiatives are ultimately governed by the same capital logics as the development of Downtown Dubai, Emirates City, and Tamansourt. Indeed, urban speculation thrives on the tension between similarity for the purpose of exchangeability and a constant hunt for market advantages through differentiation, producing capital gains by propelling a belief in growing demand and desire. Whether in the cases of the shining success stories of Dubai, the fates of its countless struggling epigones, or the emerging market of crowdfunded urban projects, speculative architecture, as a key currency used in these developments, is structured around operations rather than sites or designs. It is a disturbance and unsettling not only of the field in which it operates, but also the field it leaves behind. What connects its different manifestations is the way in which the value of architecture is becoming determined by the speculative operations of this new kind of capital structure, and how it helps shape the animating truths (civic gains, alternative risk abatement, affective involvement in investments) that enable global collaborations on such projects to evolve.

Echoing Homi Bhabha's (1994: 139-70) proposition that it is always too early and too late to write about crises, investment in the built environment also often seems both too early and too late to serve the public good in today's crisis-prone real estate market. Building activity seems increasingly pressurized by the volatility of capital flows, the shifting nature of speculative investments, increased competition among businesses, regime changes, natural catastrophes, and civil unrest. However, instead of situating architecture at the beginning or the end of a process, our approach here has been to conceptualize the potential of architecture beyond the polarities of a projected 'image' or historical 'object'. In our epoch, as conventional techniques of representation have become weaker and more beleaguered, key political metaphors and paradigms are being formed within architecture or, more precisely, in processes of 'building capital' that unfold across different timescales.

When looking at the affective registers employed in this context, two stand out as the most dominant: fear and desire. This concurrence is reminiscent of the fictional character of Marco Polo in Italo Calvino's Invisible Cities, who grapples with a triangulation of imaginations, enticements, and anxieties: "Cities, like dreams, are made of desires and fears, even if the thread of their discourse is secret, their rules are absurd, their perspectives deceitful, and everything conceals something else" (Calvino, 1974: 44). Even though these sentiments may appear contradictory at first, their interaction forms one of the most widely used modi operandi to coerce people into capitalist participation, thereby activating a key force of expansionist markets: rising demand. Real estate markets in particular thrive on speculation about excessive value acceleration in a hyped-up bubble of accumulation and resale. In the case of speculative urbanism based on large-scale top-down investment, this places a heavy burden on the performance of architecture. Nothing less is requested than the transformation of supply-led development into a demand market. In this process, architectural aesthetics becomes the preferred means of projecting the reward of speculative investment, the beacon 
showing how fear and anxiety can be transformed into something thrilling and desirable; albeit, the outcomes are far from secured, as the struggling development of the Emirates City and the changes to the project design of Tamansourt make apparent.

This dual psychological concept finds a ready subject in populations that are being simultaneously animated and threatened by global acceleration. The corresponding spatial typology combines the architectural props of a glamorous lifestyle, epitomized by images of sweeping views and free-flowing spaces, with the enclosure of that very same space by impregnable fortifications and high-tech securitization. The 'island architecture' of controlled access and gated communities compensates for the experienced loss of belonging. Whether it is the descendants of Asian and Middle Eastern diasporas feeling increasingly unwelcome in their host countries, members of the middle class in the West losing their accustomed privileges, or wealth-aspiring entrepreneurs from eastern Europe to Asia, the abstract commodity of investment in remote real estate paradoxically promises them a territorial refuge from the destabilizing effects of the worldwide economic realignment from place-based development to fluid global capital. Through this tension between a concrete material habitat and a globally tradable share in a virtual market of real estate speculation, the dual forces of fear and desire are upholding the momentum of expansive markets. The material presence and mediated aesthetics of architecture - the poster images of exclusive villas and glossy advertisements for fancy-named developments - combined with the promise of a safe pension plan or residency visas for property owners, fabricate an irresistible selling point. The painted picture of smug investment not only helps to camouflage rising fears of destabilization, the spread of war, and impending loss of wealth, but also promotes a feeling of intelligence and belonging to those in the know.

What has become increasingly clear in recent years, though, is that the phantasm of capital salvation is not merely an issue of alluring marketing techniques, but the guiding principle on which fending off losses through expansive speculation is founded. Speculating with dreams - engaging economically with the representational riddle that Calvino's protagonist sees in cities - becomes the escape route out of looming deprivation and destruction. In this sense, the experience of crisis is neither simply an unfortunate interlude nor, if intrinsic, only a cyclical occurrence of the market economy. Rather, it lies at the core of expanding investment markets. The monumental operations of even the most glamorous investment portfolios are always already geared toward compensating for underlying fears of disintegration. Fragmentation and temporariness are the main characteristics of these operations, as is the cultivation of ever-new spatio-economic frontiers through an increasingly affective repertoire of building-investment opportunities. If alternatives to our current situation, as some suggest, lie with new social movements, bottom-up urban engagement, and the emergence of alternative urban economies, then it follows that the question of control over the temporalities, rhythms, and thrust of such global interaction will have to be at the heart of political struggle.

\section{Notes}

1. On these topics, see Massey (2007) and Roy (2010); Hardt and Negri (2001) and Liberti (2013); and King (2004) and Palan (2003), respectively.

2. Key to opening up this market was a decree by Sheikh Mohammed bin Rashid Al Maktoom in May 2002, which permitted foreign investors to aquire property in selected projects by governmentrelated developers such as Emaar (the developers behind Downtown Dubai) and Nakheel (the 
developers behind the Palm Islands). A new property act passed in March 2006 extended these rights to a series of dedicated special development zones. The geographic background of investors (with a sizeable proportion of investors from India, Pakistan, and Iran, as well as Middle Eastern diaspora communities) has been relatively stable thoughout the ups and downs of the real estate market. For more information, see the annual reports by the government department responsible for registering real estate transactions in Dubai (e.g., Dubai Land Department, 2016).

3. Along with 'modern gracious living' and 'substance to your dreams', 'avant-garde lifestyle' is an attribute used in the description of Emirates City properties marketed to foreign investors. See, for example, the 2016 campaign for 'Paradise Lakes Tower B7' at <http://www.irantour.org/uae/property/ajman/paradise_lakes_tower7_ajman.html/>.

4. See the long-running discussions in online forums such as the Emirates City Forum $<$ http://emiratescity.org/>, as well as a series of online petitions by aggrieved buyers to the government of Ajman, including 'Ajman Real-estate Regulatory Agency (ARRA) and Ajman Government: Refund our Money' <https://www.change.org/p/ajman-real-estate-regulatory-agencyarra-and-ajman-government-refund-our-money-2/>.

5. Postulating different dimensions that characterize global connectedness, Arjun Appadurai (1996) uses the term 'financescapes' to describe the cultural flows associated with global capital. In his argument, "the critical point is that the global relationship among ethnoscapes, technoscapes, and financescapes is deeply disjunctive and profoundly unpredictable because each of these landscapes is subject to its own constraints and incentives (some political, some informational, and some technoenvironmental), at the same time as each acts as a constraint and a parameter for movement in the others" (Appadurai, 1996: 34).

6. While tracing the development of the economic-governmental vocation of Western democracies more generally, Agamben refers specifically to how modern Western powers have managed to impose a set of rules and regulations on other nations by making them put into practice models and frameworks that benefit the West. In his view, the 'economy' of government - the form that power has assumed in Western democracies today - is what is constituted through this functional correlation (see Agamben, 2011).

7. Flourishing as a political movement in France, Italy, Spain, and several Latin American countries at the beginning of the twentieth century, syndicalism aimed to replace the capitalist order with an economic system based on worker ownership and management of multiple production units.

8. A prominent example of measures taken in the US to enable these new flows of capital is the 2012 JOBS (Jumpstart Our Business Startups) Act, which aims to boost economic growth by easing security regulations around small-scale investment.

9. Apart from the first crowdfunded skyscraper, BD Bacatá, and the many real estate projects in Manhattan and Brooklyn (One Brooklyn Bridge Park, for instance), prominent examples also include the LowLine, a crowdfunded underground park on the Lower East Side of New York City; the Homegrown Cities project in Mumbai, initiated by URBZ and funded via Indiegogo; the collaboration between Helsinki municipality and Brickstarter, an urban crowdfunding platform, which was conceived by the Finnish Innovation Fund Sitra; and +POOL, a public swimming pool on New York's East River that combines civic aspirations with innovative engineering.

10. Slogans quoted from the advertising video for 'BD Bacatá', published by Prodigy Network (2012).

\section{References}

Adams, J. (2011) Occupy time. Critical Inquiry [Online], 16 November. Available at: <http://critinq.wordpress.com/2011/11/16/occupy-time/>. Accessed 26 January 2018. 
Adams, J. (2012) Occupy Time: Immediacy and Resistance After Occupy Wall Street. New York, NY: Palgrave Macmillan.

Agamben, G. (2011) The Kingdom and the Glory: For a Theological Genealogy of Economy and Government, translated by L. Chiesa. Stanford, CA: Stanford University Press.

Al Jandaly, B. (2008) Ajman freezes freehold visas. Gulf News [Online], 10 October. Available at: <http://gulfnews.com/business/property/ajman-freezes-freehold-visas-1.136561>. Accessed 26 January 2018.

Appadurai, A. (1996) Modernity at Large: Cultural Dimensions of Globalization. Minneapolis, MN: University of Minnesota Press.

Benjamin, W. (2010) Werke und Nachlass, kritische Gesamtausgabe. Vol. 19: Über den Begriff der Geschichte. Berlin: Suhrkamp.

Bhabha, H. (1994) The Location of Culture. London: Routledge.

Bourdieu, P. (2005) The Social Structures of the Economy. Cambridge: Polity Press.

Calvino, I. (1974) Invisible Cities, translated by W. Weaver. New York, NY: Harcourt Brace \& Company.

Chiapello, E. (2015) Financialisation of valuation. Human Studies, 38(1): 13-35.

Datta, A. and Shaban, A. (2016) Mega-urbanization in the Global South. London: Routledge.

Dubai Land Department (2016) 150 Nationalities invested AED 135 Billion in Dubai's real estate market in 2015. Dubailand.gov.ae, 18 January. Available at:

<http://www.dubailand.gov.ae/English/MediaCenter/Pages/news-viewer.aspx?nid=329>. Accessed 26 January 2018.

Dunham-Jones, E. (2009) Free trade zones, downtown financial cores, and sprawl: the landscapes of globalization. In: Owen, G. (ed.) Architecture, Ethics and Globalization. London: Routledge, 17-29.

Easterling, K. (2005) Enduring Innocence: Global Architecture and Its Political Masquerades. Cambridge, MA: MIT Press.

Elsheshtawy, Y. (2010) Dubai: Behind an Urban Spectacle. London: Routledge.

Esposito, E. (2011) The Future of Futures: The Time of Money in Financing and Society. Cheltenham: Edward Elgar.

Goldman, M. (2011) Speculative urbanism and the making of the next world city. International Journal of Urban and Regional Research, 25(3): 555-81.

Graham, S. and Marvin, S. (2010) Splintering Urbanism. London: Routledge.

Hardt, M. and Negri, A. (2001) Empire. Cambridge, MA: Harvard University Press.

Harvey, D. (1981) The spatial fix: Hegel, von Thünen and Marx. Antipode, 13(3): 1-12.

Harvey, D. (2001) The Spaces of Capital: Towards a Critical Geography. New York, NY: Routledge.

Howe, J. (2009) Crowdsourcing: Why the Power of the Crowd is Driving the Future of Business. New York, NY: Crown.

King, A. (2004) Spaces of Global Cultures: Architecture, Urbanism, Identity. London: Routledge.

Liberti, S. (2013) Land Grabbing: Journeys in the New Colonialism. London: Verso.

Marazzi, C. (2011) Capital and Affects. Cambridge, MA: MIT Press.

Massey, D. (2007) World City. Cambridge: Polity Press.

Massolution and Crowdsourcing.org (2015) 2015CF-RE Crowdfunding for Real Estate. Available at: $<$ http://reports.crowdsourcing.org/index.php?route=product/product\&product_id=52>. Accessed 26 January 2018.

McClanahan, A. (2016) Dead Pledges: Debt, Crisis, and 21st Century Culture. Stanford, CA: Stanford University Press.

Merrifield, A. (2014) The New Urban Question. London: Pluto.

Mezzadra, S. and Neilson, B. (2013) Border as Method, or, the Multiplication of Labor. Durham, NC: Duke University Press.

Mooshammer, H. and Mörtenböck, P. (2016) Visual Cultures as Opportunity. Berlin: Sternberg. 
Moretti, E. (2012) The New Geography of Jobs. New York, NY: Houghton Mifflin Harcourt.

Palan, R. (2003) The Offshore World. Ithaca, NY: Cornell University Press.

Prodigy Network (2012) BD Bacatá: The biggest product in the world. Youtube.com, 17 December. Available at: <https://www.youtube.com/watch?v=As4HWLOrE8g>. Accessed 26 January 2018.

Ramos, S. (2010) Dubai Amplified: The Engineering of a Port Geography. Farnham: Ashgate.

Roy, A. (2010) Poverty Capital: Microfinance and the Making of Development. London: Routledge.

Sassen, S. (2012) Expanding the terrain for global capital. In: Aalbers, M.B. (ed.) Subprime Cities: The Political Economy of Mortgage Markets. Oxford: Wiley-Blackwell, 74-96.

Schönig, B. and Schipper, S. (2016) Impacts of the Global Financial Crisis on Cities in Europe. Berlin: TdZ.

Simone, A. (2010) City Life from Jakarta to Dakar: Movements at the Crossroads. London: Routledge. Soules, M. (2016) Financial formations. In: Thomas, K.L., Amhoff, T. and Beech, N. (eds.) Industries of Architecture. London: Routledge, 199-210. 